\title{
EDITORIAL
}

\section{The Internet is Unwell... and Will Not Be at School Today: Oppositions, Omissions and Online Anxiety}

\author{
David Mathew, MA \\ Centre for Learning Excellence \\ University of Bedfordshire \\ Luton, Bedfordshire \\ England
}

\section{I ntroduction: An Abstract through a Negative Lens}

It might be useful to be explicit about what this paper does not contain. This paper will not contain hearty recommendations of online learning from seasoned professionals in the field, or from the confident learners who have been lucky enough to work with them. This paper will not contain a defence of online learning (neither, however, is it intended as an attack on the same, or as an evagination of the manifold accounts of successful online learning projects that bespatter the World Wide Web). It will not contain a comprehensive overview of online learning practices around the globe (assuming that such a study would be possible at anything less than book length, anyway). Nor is this paper's ambition (or that of its author) such that a more localised examination of the online learning environment in UK Universities has been undertaken. Instead of any of the above, this paper presents a picture of a Fragile Learner, struggling and anxious in the online milieu, and

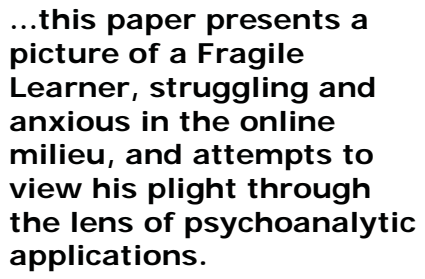

attempts to view his plight through the lens of psychoanalytic applications. In the course of researching this work, however, the author discovered a good deal of anxiety among colleagues who had been asked to work in this way for the first time in an attempt to meet learner demand. Using transcripts of short interviews with three anxious colleagues, the aim is to show how debilitating an enforced teaching role on the Internet can be, and we apply to the learning process the theoretical work of Carl Rogers, Jacques Lacan and John Steiner. We discover that Rogers had discussed the Fragile Learner as long ago as the middle of the previous century, in all but name; and by employing a stitchworked tapestry of anecdotes and memories, the former of which are accurate and the latter of which are subject to the customary erosion caused by time, self-protection and chronic narcissism, the paper refers to a learner's shame and humiliation in online learning.

\section{A Reflective Return to Absence}

In 2011, I published a paper entitled "The Absence of E", in which I compared the experiences that I had had with two specific learning programmes. One of these had learners enrolled who had no access to the Internet whatsoever (they were detained, at Her Majesty's Pleasure, in a maximum-security prison for Young Offenders aged 18 to 21), and the other had learners enrolled who only had access to the Internet and not a single meeting with their tutor. Anecdotally accurate and scientifically questionable, the paper provided the expected (and desired) split reactions of apoplexy and high praise when I presented it to a large crowd in Italy in the same year. I argued that in these specific examples - with acknowledged differences in academic subject matter, academic level, age group, geographical location, and so on (there was scarcely a control factor in sight!) - the learners on the Internet-only course, with their academic levels capped at a preMasters plateau, experienced no obvious sense of deprivation in their pedagogic 
endeavours. Banned from using the Internet because of the natures of their crimes, their distance learning programmes consisted of solitary study in their cells and then a weekly group meeting with a facilitator (me), at which their issues were resolved, their essays printed out, and then the essays would be sent by regular postal services to the people who would grade the work. I argued that as a result of this model, the learners were able to channel their dammed-up anxieties into one factotum every week (again, me) and that the teachers (at a distance) were oblivious to any negative emotions and feelings of insecurity that the learners were not shy to show in the classroom setting. "(W)ould this task group have benefited from regular access to the Internet?" I asked rhetorically (Mathew, 2011, p. 482).

Possibly it would have lent each learner more of a sense of autonomy, the acquisition of which might have led to a more determined approach; but it is plain to see that it was not the medium of travel that was the problem it made no difference if the assignment was sent by email or handed to me to put in the post - the problem was me. Or more specifically, the problem was whoever happened to be in my shoes, in front of those distance learners once a week. My very presence was a shortcut (or so they believed) to the right answer, or to the right way of researching something; with nobody to guide them, arguably, these learners' experiences would have been more honest and more robust. A human intermediary between the learners and their (numerous and unseen) teachers was a mere substitute for the Internet. They already had all of the papers and materials that were required; it is my contention that the Internet might even have got in their way and hampered their progress (Mathew, 2011, p. 482).

By contrast, the programme that was delivered entirely online consisted of learners who were able to direct their anxieties, fears and complaints directly to the primary educator, via the Web. Despite the existence of online services designed to support our learners with issues outside the main course of study, the students enrolled in overseas settings used the teacher, not only as the first port of call, but very often as the only port of call. And while it is not possible to quantify anxiety precisely, it seems evident that the overseas learners, with no access to their tutor, exhibited a good deal more angst than even the learners in the prison with their one day a week with their facilitator (which, in turn, as above, was not even noticed by their actual teachers outside the prison walls). From these observations, I concluded that learners without access to the Internet on a distance learning programme were not disadvantaged; that educators teaching on such a distance learning programme were spared the anxiety of their online colleagues; and that the online tutor takes on more than a pedagogic role - he or she is often obliged to take on a pastoral responsibility, whether or not he or she has been trained in such matters or has any willingness to engage in this field of specialism. Again, I wondered aloud:

Has a distance learning programme succeeded if it cannot claim to have offered relevant pastoral support for learners...Should a distance learning programme plan the pastoral role that is sometimes required by students? While working at the prison I was able to contain such issues, were they ever to arise, but it might be argued that the Internet, while providing a safe and (largely) efficient mode of delivery, paradoxically creates further challenges by making feedback too easy and embedding a certain (over?) sensitivity to students' needs. (As Obholzer (1994) paraphrases neatly: 'responsibility is terrifying' (p. 172).) The broad question, in a nutshell, might be: Where does the pastoral role fit in with the role of the distance learning lecturer? ...Do we need to be better aware about the links 
between pedagogy and the containment of learner anxiety? (Mathew, 2011, p. 485)

The Absence of E (2011) was a highly subjective and personalised account, of course, and it delivered me into a small amount of very small-scale trouble, part of which was its very intention. (If you can't set the cat among the pigeons at an international conference, then where can you do so?) However, the conclusions that were drawn back then (three years being a long span in technological terms) are all the more valid today. Despite the ease with which we might have assumed to have taken to online learning by now, there are doubts that thrive; there exist anxieties that only experience in the medium will placate, with words of reassurance seeming redundant and even self-negating. "When the farthest corner of the globe has been conquered technically," I quoted Slavoj Žižek as saying

and can be exploited economically; when any incident you like, in any place you like, at any time you like, becomes accessible as fast as you like; when, through TV 'live coverage' you can simultaneously 'experience' a battle in the Iraqi desert and an opera performance in Beijing; when, in a global digital network, time is nothing but speed, instantaneity; when a winner in a reality show counts as the great man of the people; then, yes, still looming like a spectre over all this uproar are the questions, What is it for? Where are we going? What is to be done? (Žižek, 2008, p. 274)

\section{Rogers and the Fragile Learner}

I had arrived at the term "Fragile Learner" and had defined it privately with a view to writing about it (or about him or her) long before I read Elizabeth Chapman Hoult's exemplary work on academic resilience and the resilient learner, Adult Learning and La Recherche Féminine (2012). To no man do I bow in my admiration of this work, but I mention it for reasons other than simple respect. Proving that ideas are in the air for anyone to pluck (a conceit shored up, perhaps, by the startling similarities in the views offered by the interviewees herein), Hoult and I had chosen to concentrate on facets of our learners that had not been explored in any great detail up to that point. Where Hoult's work focused (inter alia) on strategies employed by adult learners that serve to keep them in education, my own focus was on the reasons why learners struggle specifically on online programmes - these reasons being geographical, cultural, socialeconomical, and so on. When I co-wrote the paper entitled "Distance Learning Students: Should we use Technology or Pedagogy to

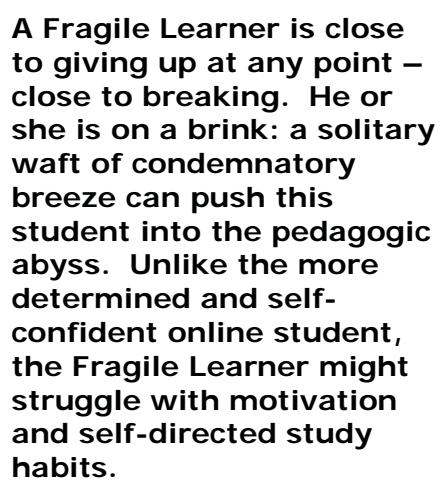

A Fragile Learner is close to giving up at any point close to breaking. He or she is on a brink: a solitary waft of condemnatory breeze can push this student into the pedagogic abyss. Unlike the more determined and selfconfident online student, the Fragile Learner might struggle with motivation and self-directed study habits. Overcome Work and Life" (Mathew \& Sapsed, 2012), for example, we were thinking of the Fragile Learner in all but name. In this paper we discussed "the stories of three learners on the distance learning option of a Masters degree in Public Health, which is offered by a University in the United Kingdom. These learners were challenged by obstacles related to their employment," and the paper "outline(d) some of the technological and pedagogic strategies that were employed to address these challenges. In a highly reflective manner we present(ed) findings that might suggest little more than common sense - that with distance learning programmes, both technology and pedagogy are vital components but are interdependent on one another - but we hope(d) to show ways in which an academic tutor online assumes roles that are often beyond the customary scope of teaching: he or she is frequently obliged to assume pastoral 
care roles that might be better suited to a counsellor or a professional in a different industry."

A Fragile Learner is close to giving up at any point - close to breaking. He or she is on a brink: a solitary waft of condemnatory breeze can push this student into the pedagogic abyss. Unlike the more determined and self-confident online student, the Fragile Learner might struggle with motivation and self-directed study habits. He or she might also struggle with the technology itself - or with the notion of being forced into online groups for the purposes of completing a task. Time management might be problematic; the ability to conduct research and to communicate through writing even more so.

The notion of such a precarious, knife-edge modus operandi is not new, however, although it might be shunned often as a modish concern. Indeed, we can refer to the middle of the twentieth century for a glimpse of what I have termed fragility. No lesser figure than Carl Rogers might well have been discussing the Fragile Learner in the Fifties. For although he did not use the term fragile learner in his "explosive" paper entitled "Personal Thoughts on Teaching and Learning" (Rogers, 1958), this work contains a compressed blueprint of the traits and characteristics that such a learner exhibits. The interesting thing, in addition, is that the paper's only personal subject (and provider of sensory evidence) was the author himself. Similarly, the adjective "explosive" was Rogers's own reflection on his work's reception at a Harvard conference. But why was the paper so challenging? One interpretation might be that even now, nearly sixty years on, its unrelentingly pessimistic tone on the twinned topics of teaching and learning remains shocking. Delivered as it was at Harvard of all places (an expensive seat of education), the paper's banner of futility was a source of professional outrage.

What does it say? Rogers prefaces his thoughts with a paragraph in which he implies, in a somewhat self-deprecatory manner, that none of what will follow is to be taken generally or non-specifically: what follows are opinions, nothing more and nothing less:

I find it a very troubling thing to think, particularly when I think about my own experiences and try to extract from those experiences the meaning that seems genuinely inherent in them. At first such thinking is vary (sic) satisfying, because it seems to discover sense and pattern in a whole host of discrete events. But then it very often becomes dismaying, because I realize how ridiculous these thoughts, which have much value to me, would seem to most people. My impression is that if I try to find the meaning of my own experience it leads me, nearly always, in directions regarded as absurd (Rogers, 1958, p. 4).

Continuing in the same vein (of equal parts self-flagellation and expectorative satire), the author writes: "It seems to me that anything that can be taught to another is relatively inconsequential, and has little or no significant influence on behaviour" (Rogers, 1958, p. 4). At least with this statement the author adds something of an ironic caveat: "That sounds so ridiculous I can't help but question it at the same time that I present it."

"I realize increasingly that I am only interested in learnings which significantly influence behavior," he adds; and "I have come to feel that the only learning which significantly influences behavior is self-discovered, self-appropriated learning" (Rogers, 1958, p. 4). In other words, Rogers seemed to be asking: What's the point of more formalised (more formulaic?) learning? There is nothing worth learning apart from what I discover by myself; the presence of an educator is tokenistic at best (we interpret further). Crucially, Rogers was saying that those who teach are redundant in the learner's mind; and having rubbished his own achievements as an educator, the author decides: "I realize that I have lost interest in being a teacher" and "I realize that I am only interested in being a learner, 
preferably learning things that matter, that have some significant influence on my own behavior."

There is much about the above that pertains to the construct of the Fragile Learner. Fearful in advance of a disappointing pedagogic exchange, the Fragile Learner is aided by anxiety and a pre-trauma depression to demand things on his or her terms. This might mean that he or she concludes in advance that formalised teaching is worthless; or it might mean that he or she goes into the experience with nervous trepidation, already resigned to the option of a painless retreat when matters become difficult, at which point he or she can blame the teacher or technology, safe in the result of a self-fulfilling prophecy: if I believe that something is bad before I experience it, it will be bad. This might even qualify as an application of the psychoanalytic concept of projection, as defined by Laplanche and Pontalis as an

operation whereby qualities, feelings, wishes or even objects, which the subject refuses to recognise or rejects in himself, are expelled from the self and located in another person or thing. Projection so understood is a defence of very primitive origin which may be seen at work especially in paranoia, but also in 'normal' modes of thought such as superstition. (Laplance \& Pontalis, 2006, p. 349)

The Fragile Learner, primed by anxiety, might be unconscious of, or successful at managing, feelings of self-hatred and the fear of failure. On experiencing this very same failure, he or she "projects" the feelings on to another "guilty party." And although aggressive conduct is outside the purview of this paper, it is worth noting, parenthetically as it were, that the Fragile Learner does not always know how to behave with civility while online. The antagonistic nature of some participants to online interactions lends credence to the notion that there are those who support an internal system of beliefs surrounding the idea of voluntary violence. In the life of someone who already maintains something of a marginalised existence, we might easily believe that emotions overwhelm the capacity to rely on a rational response; self-destructive behaviours are apt to be precipitated.

At the heart of any such systems - as a general rule - will be anxiety.

\section{Interview 1}

The three interviews that punctuate this paper were conducted in identical circumstances. All three subjects work inside the Faculty of Health and Social Sciences. All three subjects had been required to undertake some of their teaching commitment online for the very first time. Although the questions that were asked were the same, for the sake of completion and flow, other comments that add to the overall picture have been left in. Other comments that are not pertinent to this paper and refer mainly to other issues have been excised.

Interviewer (I): What is your experience of online learning, either as a learner or as an educator?

Subject 1 (S1): From a learner's point of view, I have done a number of online packs. From a university point of view, the mandatory training type of packs, and also being enrolled on the LEAN Institute healthcare - I had to do a few packs with them, looking at service improvement, as a student.

I: What were your general impressions of them as a student?

S1: I quite enjoyed doing the packs. To me they're a form of escapism. When I ought to be working and I can't concentrate on other things, I go on to do a pack because it takes me away from the shop floor, if you like, and I can do something positive.

I: As someone new to online learning, were the packs organized well enough that you could follow them easily? 
S1: Yes, on the whole. I think, one of the downsides is, with some of the questions you can remember the answers, so you can quickly whiz through them, having remembered the answers (from a previous visit to the resource).

I: So these were predominantly question-and-answer-type packs?

S1: Yeah. I find them quite helpful. I think, from an educational point of view, online packages are a great way forward.

I: With that in mind, would you be happy to take on more responsibility for other learning packages going online?

S1: Yes, I would be quite interested. In the reorganization that we had in 2012, there was a role for online learning and there was one half of me that would have been interested in that. It would have been my second choice in terms of roles and responsibilities.

I: If you think back to before you taught online, when you first thought about teaching online, how did you feel then?

S1: Terrified. When I first thought about doing a distance learning pack, I envisaged the old Open University model, with books and packs, and that's what I had in mind. When (my manager) started talking about e-books and the like I nearly freaked! I thought, 'I can't do this!' I'm not brilliantly computer literate and I didn't know how it would be set up, and I was in a complete panic about it.

I: Did you see being computer literate as a necessary part of offering an online course?

S1: I thought you'd have to be. I don't know enough about computer programs to know how much I would need to be involved in the development side of it. I thought, "If anything goes wrong, what do I do?" It was that kind of thing. I didn't know what support there was.

I: Why do you think you thought this way at the time?

S1: I didn't know what kind of support there was out there. I thought, "If I go online and something goes wrong, I'm leaving the students in limbo without a package working - electronic things, if a system crashes, what kind of back-up there is." I was scared about that side of things.

I: I think we can agree that the most unpredictable thing about any educational interchange is the person. The most predictable is the technology. It will either work or it won't work. There's no kind of middle bit. People are endlessly variable; technology isn't. So did you think, "I don't have a back-up plan if this doesn't work?"

S1: Yes, but also, having got it online, you think - with any organization something new comes in and you try it, and the support is there initially but then it goes. I was worried about being left in limbo with students shouting at me, saying that these packs don't work.

I: Have your feelings changed since the course started - or more specifically, since you started teaching online?

S1: Definitely. I think the support you've given me is absolutely magnificent.

I: Thank you; that's very kind.

S1: I think your enthusiasm for it has made me want to take it on more...and going back to a question you asked me earlier, I think if you hadn't been as supportive as you were, I think I wouldn't. I know there's someone behind me, and you've given me confidence to go ahead and do this. I'm dreading the day when you send me an email saying you're moving on (to another job). People do move on and I'd be absolutely lost without you.

I : How do you feel about online learning now?

S1: I think it's a brilliant concept. Concept's the wrong word. Approach. But I do have some concerns. In terms of engagement...J know we've talked about students having certificates when they complete courses (i.e. certificates generated automatically upon completion of the online tasks). That would be something, from my point of view, that would be useful to stay students have done this. In terms of underpinning learning, the way computers are going now, you can have Blackboard now and BREO now on mobile phones and tablets, take them anywhere - instead of 
books and documents (which are harder to transport). As a way of learning, it's really positive.

I: What do you think is the future of online learning?

S1: I think it's going to be around for a long time. I think it's going to get more technical. To me, it's probably the way forward in terms of student attraction, in terms of student numbers - because I can see we can work with overseas universities - and I think as long as you can build in a way of checking that students are engaging...as long as you put in safeguards...For the (name of the course), the students submit a (physical, hard copy) portfolio, so they've passed from that point of view. Possibly if we could get a discussion board going, and I could chip in every now and then...The last time I tried it, it was really a one-sided feedback. The students didn't discuss anything with each other; it was all directed at me.

\section{Anecdotal Gobbet the First}

As part of an online course about online learning in 2014, I was invited to contribute my thoughts to a video filmed by a female student of approximately nineteen years of age. I wrote:

Hello, everyone. I 've posted a couple of thoughts about Scenario 2 below, but one thing I don't think has been mentioned is the student's response in Scenario 1. Although she has technology at her disposal, I would argue that she doesn't seem particularly happy with what she's been able to achieve. Now, granted, some of this might have been for the benefit of the camera; but perhaps it should be noted more often than it possibly is: the realisation that not even what we have access to now will be sufficient for some of our students; that it won't be fast enough or loud enough, etc. How do we, as educators keep up with student demand even if we DO fully embrace the notion of mobile learning or new advances?

\section{Crash Course in Anxiety}

The study of anxiety is at the root of psychoanalytic explorations of the human condition. Given that psychoanalysis is a field in which an adult's problems, however outlandish or outré, can be "explained" or qualified by the discovery of an event (or series of events) in that person's childhood, it is not difficult to believe that an anxiety about learning per se can also be rooted in one's babyhood or infancy. But what is anxiety? From the acres of literature on the subject, it is easy to determine that the definition has no simple

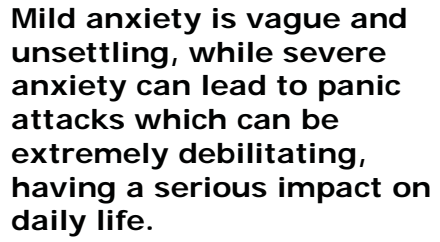

consensus. In the same way that we might disagree on what individually we have self-diagnosed when we utter the sentence "I have a cold," we are likely to be discussing different matters when we confess to sensations of anxiety. Let us attempt, however, to sum up the findings.

Often triggered by events that are unique to an individual, anxiety is a term used to describe a number of psychological conditions. It is something experienced, to one extent or another, by every man, woman and child, and arguably even by some animals (separation anxiety in pet dogs and horses, for example). It is the sensation of stressful expectation that one feels for no apparent good reason; the gloomy dread with which one sometimes wakes up in the middle of the night. As a state of worry or nervousness, anxiety is often accompanied by a vague unpleasant feeling that something bad is about to happen. Mild anxiety is vague and unsettling, while severe anxiety can lead to panic attacks which can be extremely debilitating, having a serious impact on daily life...For the purposes of this submission, we will be clear to distinguish anxiety from stress: they are not the 
same. Nor is anxiety a synonym for fear, although the terms are often used interchangeably.

Among the many thousands of words on the subject penned by Sigmund

Freud, his description of anxiety as having an "unpleasurable character" in Introductory Lectures on Psychoanalysis (Freud, 1916) seems like a masterpiece of understatement. However, a decade later, he gave us a full-length exegesis of anxiety, which is often cited to this day. "If a mother is absent or has withdrawn her love from her child," he writes, "it is no longer sure of the satisfaction of its needs and is perhaps exposed to the most distressing feelings of tension" (Freud, 1926 , p. 87) According to Martin Heidegger, "anxiety is characterized by the fact that what threatens is nowhere and nothing" (Heidegger, 1962, p. 231); whereas Melanie Klein cites the Grandfather of Psychoanalysis when she

f..the internet can make us parental function to reduce states of internal tension.

writes: "Freud put forward to begin with the hypothesis that anxiety arises out of a direct manifestation of libido" (Klein, 1948, p. 25). She expands this opinion by stating that "in young children it is unsatisfied libidinal excitation which turns into anxiety" and that "the earliest content of anxiety is the infant's feeling of danger lest his need should not be satisfied because the mother is 'absent'" (Klein, 1948, p. 26). Klein had previously written: "In early infancy anxieties characteristic of psychosis arise which drive the ego to develop specific defence mechanisms" (1946, p. 1) - which made a link between anxiety and the systems of defence that we use in troublesome situations, or in the predictions of troublesome situations. She makes it clear in the later of these two papers that her belief is that "anxiety is aroused by the danger which threatens the organism from the death instinct" and that "anxiety has its origin in the fear of death" (Klein, 1948, p. 28). She adds

if we assume the existence of a death instinct, we must also assume that in the deepest layers of the mind there is a response to this instinct in the form of fear of annihilation of life...the danger arising from the inner working of the death instinct is the first cause of anxiety. (Klein, 1948, p.29)

Childhood is, of course, the time when we learn many of the lessons that we take with us throughout our lives. Meltzer informs us that "the anxiety apparatus is a vital tool in the hands of the ego for the achievement of learning and the accomplishment of maturation" (1955, p. 11) and that "the capacity of anxiety is innate in the mental apparatus" (Meltzer, 1994, p. 6). In the child's very early years, when he is unable to "distinguish body from external object, the infant cannot...experience yearning towards or frustration by, but only distress" (Meltzer, 1994, p. 6). This distress is closely linked to "two forms of anxiety, persecutory and depressive, (which) are the primitive forms and the prototypes for later objective and instinctual anxieties. The distinction between the primitive and mature forms is founded on the degree of reality underlying them" (Meltzer, 1994, p. 9). Anxiety for a child might occur at a moment of indecision, emotional imbalance or ambivalence: the moment when he understands that the mother who deserves his hatred is the same as the mother who deserves his love.

In more ways than the obvious (our subjugation to a superior other occurring simultaneously with a transient sense of self-worth and power), we are all children understanding our mother's identity when we contemplate the World Wide Web. It is nigh-on impossible to ignore it, after all; it is easy to hate it for the time it wastes, for our slavish dependence on it; and yet, how we smile when we find that nugget of information! In the case of the latter, the cessation of anxiety is the result of an awareness of jouissance (see below for a section on Jacques Lacan, who popularised the term jouissance in psychoanalytic circles to mean a form of complicated happiness). Furthermore, the Internet can make us feel helpless; it 
takes on a parental function to reduce states of internal tension. To a certain extent, anxiety is a warning against insanity; also it is a soporific.

Meltzer tells us that our acquired anxieties are indeed based on expectations and predictions. "When the objects are not performing in the expected way - that is, when they have become bad and persecuting - the infant is unable to form a prospective phantasy of relief" (Meltzer, 1994, p. 7); and "when a prediction that is of importance with regard to plans for relief of tension fails, the phantasy that results is of the current tension extended in time. The content of this phantasy will extend to eternity until a new prediction is formulated" (Meltzer, 1994, p. 9). Meltzer also points to the link between anxiety as a condition and the illness that it might precede. "But the warding off of anxiety is quite another matter," he writes,

Here the ego...adopts a policy never again to experience some specific anxiety phantasy and its affect. This is quite a serious determination, for such a policy implies the abandonment of maturation within the lifespace compartment involved. The result is a functional disease. (Meltzer, 1994, p. 11)

Here, 'affect' might be defined as an emotional response.

However, anxiety is a useful emotional commodity: it is more than the inappropriate switching on of a "flight or fight" response to deal with a threat to one's survival - a threat that might not even exist. In common with the brains of our primitive forefathers, the brain scans one's environment for threats but it cannot always tell the difference between a real threat and a perceived threat, and so both possibilities are treated in the same manner. A region in the brain called the amygdala "connects" the two situations and forms an unconscious memory of the association. When a stimulus occurs later, the amygdala is activated in the same way

Yet, ironically, the physical space in which the learner works deprived of human interaction, for example - could easily provoke tensions of entirely the opposite, claustrophobic kind. The learner's irrational fear, however, is precisely of that which cannot harm him, which is one reason why it qualifies as an example of anxiety.

that it was in the presence of the original threat. Similarly, when one is in a situation somewhat like a situation of threat from the past, the brain notes the similarities and triggers the flight or fight response again, even if such a response is not called for. Anxiety might manifest itself as a sense of mounting physiological arousal, or as bodily and thinking symptoms - a headache, a stomach ache, the inability to recall something that is seemingly important. How, then, can anxiety be considered important in an educational milieu?

Building a relationship between motivation and anxiety, we might agree that one needs an optimal quantity of pressure under which to work and learn. One's performance (linked to one's sense of personal wellbeing) is achieved at a moderate level of emotional arousal: if the arousal is too little, the result is boredom, and if the arousal is too much, the result is anxiety. Both of these conditions will inhibit effective efficiency. But should this mean that no anxiety is the gold standard?

In A Critical Dictionary of Psychoanalysis, Charles Rycroft writes that

the usual definition of anxiety as irrational fear applies strictly only to phobic anxiety, which is evoked by objects and situations such as open spaces, closed spaces, heights, spiders, snakes, thunder, travel, crowds, strangers, etc., to an extent which is out of all proportion to their actual danger. (Rycroft, 1995, p. 8)

Examining the category of phobic anxiety for a moment, a comparison is within easy reach, albeit a comparison on the level of metaphor. The "irrational 
fear...evoked by objects and situations" is one that we can imagine a student (or colleague) suffering, faced as he or she is by the situation of cloistered study in an online and possibly alien environment. The object is a screen on which unexpected material appears at the press of a button, or worse still fails to appear as a result of user ignorance; or the object is a keyboard, on which letters of the alphabet have been arranged in a peculiar order (especially if the student is not used to typing). In fact, any individual item of the learner's hardware or physical environment - the mouse, the chair, the desk - can be elevated to the order of object in the mind of the anxious Fragile Learner. Then again, so can virtual objects - the icons, the onscreen folders that are difficult to unpack - and let us not forget the resonance of the word object itself, particularly when uttered in Freud's accent, with his influential and ghostly breath in our ear.

The examples that Rycroft uses, furthermore, are similarly apposite. Stripped down and seen in the light of a largely solitary experience, online learning is one person, a device, and a virtual doorway onto a cosmos of information. It is entirely understandable, surely, that a learner might regard this virtual open space - the Internet - with at least a modicum of agoraphobic tension. Indeed, it is an opinion that might well have been shared by Gaston Bachelard in The Poetics of Space. Commenting on the anxiety of open spaces, he wrote: "Here fear is being itself. Where can one flee, where find refuge? In what shelter can one take refuge? Space is nothing but a 'horrible outside-inside'" (Bachelard, 1964, p. 211).

Yet, ironically, the physical space in which the learner works - deprived of human interaction, for example - could easily provoke tensions of entirely the opposite, claustrophobic kind. The learners' irrational fear, however, is precisely of that which cannot harm him, which is one reason why it qualifies as an example of anxiety. Given that it is impossible to be directly harmed by the Internet (and as a slightly paranoiac parenthetical aside, we might feel inclined to add the qualifier 'yet', or 'at the time of writing'); and given that it is impossible to hurt the Internet (as if it were a vast and sentient beast that could be speared), it is irrational for anyone to experience anxiety at its contemplation. Yet people do - our learners and our educator colleagues among their number. The anticipation of interfacing with something so immense, something so (theoretically) infinite, is awesome. It is bigger than the conceptual capacity of our brains, the vast majority of which we either fail to use or fail to understand anyway. Given that the Internet is a matrix of a million minds, a conglomerated record of the sum of human endeavour, and the resting place of more billions of dumb ideas and cretinacious ejaculations than there are stars in the Milky Way, it is impossible to contemplate boasting of comprehending but an infinitesimal nail-paring of our Internet.

What is more, it is expanding still. While listening to BBC Radio 4 on my journey to a work appointment on 4 February 2014, I heard that the Internet would be introducing new domain names in the near future. The reason for this was not (as one might have expected it to have been) solely the result of the Internet being full to capacity - as full of vibrant websites and dead links as an ocean is crammed with pulsating existence and dead grains of sand - but also the result of demand far outweighing demand in the case of specific industries requiring their industryspecific URLs. Or to put it another way, come the very near future, the proposition is that it will no longer be sufficient to expect (say) a bookstore to lug behind it an old-fashioned dot-com or dot-co-dot-uk domain handle. Certain sectors want to be known as (again, for example) as dot-books sites from now on. If we give it time, and if the inference we draw is correct, the Internet will eventually be crammed with dot-books, dot-banks, dot-music and dot-sex sites, launched fresh and clean from the ashes of a previous World Wide Graveyard that is unlikely to tidied up this side of forever. The point surely must be more acute than a mere recognition of competing market forces: that bookstores would relish the altered economic gladiatorialism of a new Web arrangement is quite possibly no great surprise; nor is the fact that businesses with the same domain name (to a certain extent) even levels these same gladiatorial fields and pitches. What we have here, in addition, is 
an example of mutated epiphenomenalism. Where "traditional" epiphenomenalism espouses the view that mental events are caused by physical events in the brain, yet have no effects upon any physical events, what we might be encountering, as we plough the early spring fields of the 21st Century, is a situation whereby the brain's muscles have contracted after receiving their neural impulses, and the brain has now organised the movements of millions to its own ends. The brain, however, belongs to no single human mortal: the brain is the Internet itself, and it controls our times.

And time is also important to an appreciation of anxiety. Arguably, anxiety cannot 'exist' or function without time - or rather, without one's awareness of time. Even if the spell of anxiety exists only for a moment, there is likely to be an (unconscious) object from the past under mental consideration - a broken toy in one's attic, as it were - and the shortest duration of anxiety-filled time nonetheless presupposes the notion of time passing via psychic reference to a moment that might happen. By way of examples, let us consider the bereaved or the chronically chemically addicted: both groups (among many) are instructed to live one day at a time - or might tell others that this is the living pattern they have 'chosen' to adopt. Whether we agree that such a perusal of the future in bite-sized chunks is a deterrent against anxiety, or whether we suspect that such a tactic, while no doubt useful for some, is for others an invitation to depression on the instalment plan. Therefore, taken literally, anxiety about the future is actually anxiety about both an unknowable entity and a fairly abstract concept. Given these qualifications, what we refer to is really a phobia - an irrational fear of something that is unlikely directly to harm you.

\section{I nterview 2}

Interviewer (I): What is your experience of online learning?

Subject 2 (S2): Where do I start? Just from my personal point of view, my experience of it is only through my academic studies. We were introduced to a lot of online facilities because it's all about self-learning, and I suppose with the students I'm working with, they are encouraged and expected to do a bit of online learning to do their own research. In the job I have I didn't have, initially, too much involvement with that. I just left other lecturers to that, so the limited knowledge I have is from my own personal studies, when the lecturer has put course information online, so I have no choice - I can't avoid that. So I have to make myself learn to access that information and get by.

I: What courses have you been involved in with online learning?

S2: I have done the Postgraduate Diploma in Medial Education. I did the Certificate to start with and then the Diploma level. I'm embarrassed to say that to study at that level I should have a good knowledge of working online, but technology is not my strong point - I've always been frightened of it and I'm ignorant of how to navigate around those systems. When I click onto that page, where else do I go? What do I do? I suppose I'm not the adventurous type who would click on this just to see what happens. I'm from the old school where you learn from a text book; you go to the Contents page to find what you want.

I: So do you think the course was badly designed?

S2: I don't think the course was badly designed; it's just that everything is going towards technology and computers and I'm just in this time-warp and I haven't moved on. Much as I try, it's partly (that I have) no interest and partly I'm too scared. Also, there is the time factor, and finding someone who is patient enough to guide me through.

I: When you first thought about taking an online course, either as a student or as a teacher, how did you feel then?

S2: I dreaded it...but there is no choice in the matter, because the lecturer or the programme manager is saying, "The information for your course is online - log on and you'll get it." That freaked me out. It doesn't do me much good - my 
confidence - because I'm academic staff and yet I'm still struggling with that. It's come to a point where I ought to pack it in.

I: Pack in teaching?

S2: Yes. I know I'm a good teacher, and the way that I'm teaching is kinaesthetic, and the students benefit from it. Even yesterday, when we were doing simulation, they were asked in the feedback, what did you find most useful? And they answered, the session they did with me. And they left the room, all coming to me to say thank you. But it still doesn't give me any comfort because it's come to the point where (technology) is overriding all the good things I've done.

(S2 starts crying.)

I : I'm sorry, I didn't mean to make you upset.

S2: You didn't. It's not you.

(S2 presents material not relevant to this paper.)

S2: Even online marking - I've taught myself and it's slow, but I got there, with some help from yourself and from colleagues. At least I got there, but my anxiety level is up again because the next course is coming up. Previously it was five contact days with the students, but now they've reduced that and two of the days are online. As a lecturer I have to get to grips with the online before I encourage my students. The last time I taught that, I just about managed to navigate my way in and show them and that's as far as I got. I just haven't got the guts to go in and participate in the way that (the course manager) would do and interact with the students and answer their questions. I feel a failure.

I: You've kind of answered this already, but...You said that you approached your online course with dread, but why do you think you felt that way?

S2: I feel I'm incapable, or haven't got the skills, to log in and explore what's available, whereas with a text book I know I can turn the pages. With online, you have to have the knowledge or the imagination to think, okay, where can I find that information?

I: But if you're not taught how to do these things, there's a lot of assumption that you'll know what to do.

S2: Over the years, working for the University, I do feel that that's one big gap, in the sense that it's taken for granted that you know. There isn't anyone who checks that you do have that knowledge. I suppose I've got to be accountable and say, I don't know this, and go find out. I find it very frustrating. As academics, we bend our backs backward to support our students - I would do anything for my students to ensure a smooth passage for them - but for the staff there isn't that induction period. For example, we are supposed to be putting information on (the Virtual Learning Environment) for the students. I know I can go on the courses (to teach aspects of the VLE) and I went on that, but the pace was so fast that I couldn't catch up. And in those days, there wasn't a need for me to use it frequently, so I soon forgot what I learned and I struggled again. I'm only learning on the hop because when I'm desperate I've got to do it - to learn it - at the last minute. I would love to be able to say I've got the leisure to go on a course. Work commitments do not allow me the time to do anything at all. I mean, a lot of my studies, I'm doing it on my own time or on holidays. I'm told I have five days to concentrate on my studies, but every time I plan something it gets cancelled because something has cropped up. And you've got to deal with it. So you put things on the back burner - you put it even further back in the drawer.

I: I think you've answered this, but I'll ask it anyway to keep things the same (with the other interviews). Have your feelings changed since you started teaching in the online environment?

S2: My feelings about it - the anxieties and the fears - are still there. In fact, it's worse now - it's heightened - because I feel I'm being cornered into a situation where I have to get through it. It's either that or pack it in, because I hate to feel I'm doing a job and it's only fifty per cent. Or even seventy or eighty per cent. For me, if I'm doing something, it has to be one hundred per cent. Some days I know I'm being hard on myself, but I know if someone is relying on me to learn then I 
shouldn't disadvantage them. I know how it feels, as a student, to feel disadvantaged because you have to go online - you have no option - and I hate to think I'm disadvantaging my students this way. University students can get online and work it out, but the students on (a particular nursing course) - some of them are dinosaurs like me and I feel I have to help them. When I start on that course I always have to freak myself out by going on (the VLE) again - go through a rehearsal, logging in, so then I can get one of the students who has anxiety like me, and ask them to log on. I prefer them to be in control of the mouse, even if it takes some time.

I: How do you feel about online learning now?

S2: It hasn't got any better. It's even more stressful now - it's got worse. It's making me feel even more incompetent.

I: How do you see online learning progressing in the future?

S2: I think this is how the world is going to be. It's going down this electronic pathway. It's about preparing people to accept that - to work with it. Maybe I'm a defeatist; I feel like a defeatist. I feel I'm too old to lean new tricks. Or maybe I'm too stupid or too daft to learn new tricks. If I haven't got anything better to do - if I'm retired - maybe it's something I'll enjoy, learning at my own pace. But the work demand is such that I haven't got that luxury to do that. For me as a learner, trying to get on with working online, it's like working in enemy territory. There are landmines everywhere and I don't know where to tread. I could be blasted off anywhere.

\section{Anecdotal Gobbet the Second}

Every year I organise a writing retreat for colleagues at the University, on the first morning of which the participants are asked to describe, in less than two minutes, the history, rationale and proposed publishing destination of the paper that they intend to finish drafting. Even though I am explicit upfront about the fact that there will be no Powerpoint available, it is interesting to note the high percentage of people who arrive wielding flashdrives and handouts. I explain that this is "old school": that they will have to use words from their mouths and notions from their brains. The only visual aids permitted are what they might scribble or sketch at that moment.

Technology can be used as a shield, perhaps, but what happens (as it were) in the absence of E? A group of lecturers is confined to an atmosphere of first principles, under the gaze of colleagues who will almost certainly remain empathetic (because everyone will have a turn). The absence of $E$ is an opportunity to rifle through old drawers, in search of tools that have not been used in years. The crutch is kicked away, and one is obliged to recall that there was a time when one did not need it in order to walk.

\section{Lacan's Missing Pieces}

"I have opposed the psychologising tradition that distinguishes fear from anxiety by virtue of its correlates in reality," writes Jacques Lacan (1990, p. 82). "In this I have changed things, maintaining of anxiety - it is not without an object."

We are entering Lacan's bizarre world (and I do not believe that he would have been offended by my adjective), in which his seminars played to packed venues and lasted one year each; in which his unorthodox methods in the analytic session led to his name being struck from a list of training analysts; and in which Woman does not exist - in which he proved, that is, via a scientific model of his own devising, that Woman (not women) does not exist. Irascible, brilliant, difficult (in every interpretation of the word and in every life context imaginable) - not to mention being a psychoanalytic law unto himself - Lacan has been envied, feared, ridiculed and lauded for well over half a century; and although he has been three decades in the grave, the debates about his academic pugnacity versus the feasibility of his snake-oil salesman ruminations rumble on. 
Speaking and writing phenomenologically, Lacan states that "anxiety is an affect of the subject - a formula which I did not put forward without subordinating it to the functions that I have long established in the structure of the subject, defined as the subject that speaks and is determined through an effect of the signifier" (Lacan, 1990, p. 82). When we add the dimension of affect as an emotional state of being, the affect itself can be regarded as an indicator of one's reception of a transmission that emanates from without one's psychic apparatus. In Lacanian formulations, anxiety is not without an object - the object is objet petit a. In turn, the objet petit a (or "object petit a"... but always "petit a" and

At the root of our anxiety about tests... is a fear of providing the wrong response - in turn, a byproduct of a fear of being humiliated and shamed...In Lacanian terminology, we might say that questions...that one cannot answer...can cause the erosions of the ego under the gaze of the Other.

never, as we might translate it, "small A" or "lower case A") is the definite object, which is symbolic. "For the subject, there is substituted, for anxiety which does not deceive, what is to function by way of the object petit a" (Lacan, 1990, p. 8). Lacan insisted that the term should remain untranslated, believing that it would acquire the status of an algebraic sign. (Lacan, we might reasonably infer from this alone, had sufficient supplies of antibodies against modesty - as might befit a psychoanalyst of whom more has been written than any other practitioner bar Freud.) In objet petit $a$, the "a" stands for "autre" (other), and Lacan had developed it from the Freudian "object" and his own notions of otherness.

Encapsulating his ideas in miniature is like nailing water to a wall, but let us attempt to anyway, with the aid of an example. The object petit $a$ is the thing to be anxious about and simultaneously the thing that is non-existent. It is the space between what the subject does not have and what he desires to have (the latter accompanied by the anxiety of desiring it). One might hear (or say) "I am anxious about my test tomorrow." In this construction, Lacan would regard the test tomorrow as a replacement for the failure of the ego - the loss of the self. The test (in this example) becomes a symbolic image onto which we project the object petit a. At the root of our anxiety about tests (and this does not only apply to students in an exam hall either) is a fear of providing the wrong response - in turn, a byproduct of a fear of being humiliated or shamed; of being seen in the open, stripped of any academic disguise. In Lacanian terminology, we might say that questions in general and questions that one cannot answer in particular, can cause the erosion of the ego under the gaze of the Other.

In paranoia and schizophrenia, the Other occupies the position of an absolute other, and the subject, recognizing a lack in the Other but an unsymbolized one, attempts to complete the Other, since the Other's lack is unbearable, experienced as the destruction of the Other. This completion is achieved by the subject becoming the object of the Other's jouissance, the plaything of the Other... - so writes Leonardo S. Rodgriguez in A Compendium of Lacanian Terms (Rodriguez, 2001, p. 26),

a 220-page book that attempts to define Lacan's terminology alone. explain it thus:

In the same volume, a different writer, Huguette Glowinski attempts to

The subject apprehends a lack in the Other, something the Other wants. The subject locates his/her own lack at the point of lack perceived in the Other. The first object the subject proposes as the lost object or lack is him-/herself - can he/she lost me? - the fantasy of one's death or disappearance (the subject producing the lack in the Other following the course of the death drive). (Glowinski, 2001, p. 12) 
For a third opinion, I refer to Renata Salecl's extraordinary work, On Anxiety (Salecl, 2004).

Fantasy and anxiety present two different ways for the subject to deal with the lack that marks him or her as well as the Other, i.e. the symbolic order. With the help of the fantasy, the subject creates a story, which give his or her life a perception of consistency and stability, while he or she also perceives the social order as being coherent and not marked by antagonisms. If fantasy provides a certain comfort to the subject, anxiety incites the feeling of being uncomfortable. However, anxiety does not simply have a paralysing effect. The power of anxiety is that it creates a state of preparedness, so that the subject might be less paralysed and surprised by events that might radically shatter his or her fantasy and thus cause the subject's breakdown or the emergence of a trauma (Salecl, 2004, p. 47).

Furthermore, in the words of the same author, "a computer, too, can be taken as a big Other - a new type of symbolic space" (Salecl, 2004, p. 158). Our Fragile Learner, we might infer, is simultaneously drawn to the anxiety-inducing computer (and by extension, his or her studies) as a way of validating his or her academic image, and repulsed by the deficiencies that he or she finds staring back at her from the Internet's symbolic image. The Fragile Learner and the World Wide Web watch one another, enveloped in sensations of cosy gestation and alarming flashes of dread and hopelessness, wondering if he or she is good enough to embark upon the pedagogic journey that lies ahead.

The fact that Lacan elaborated on the notions contained herewith in a volume entitled Television (Lacan, 1990) is interesting; possibly it even qualifies as irony (although irony is an elastic and elusive topic in psychoanalysis). Granted, he was not writing about television (the book is at heart a transcript of his appearance on television), but we might imagine, for a moment, that he had television very much on his mind. It is easy to be "soothed" by television (as it is with the Internet): people talk of it "relaxing" them... or to put it another way, of its ability to sedate and induce (at times) a state of near-catatonic cretinization. One of the many characteristics of Lacan that we might infer is that he took it upon himself to confront the Fragile Learner. He made his students work hard; he assumed a huge stock of common knowledge before he began talking - and yet (or perhaps because of this gladiator-cum-circus-ringmaster pseud- and pseudo-arrogance) his students adored him. They knew that he was on their side during the Parisian student riots in 1968. Confrontation was a certain antithesis to fragility.

\section{I nterview 3}

Interviewer (I): What is your experience of online learning, either as a learner or as an educator?

Subject 3 (S3): As an educator, as you know, for the last two years we've had lots of blended learning - e-learning I call it - on to the (name of course) site. Working with that has been a big learning curve for me. The learners have to work through scenarios and answer questions, and they post their findings onto discussion boards. The scenarios are issues that are commonly found in practice. What I've found is there's been a real richness of replies and material they've posted, and certain sentences keep coming up - "I've never thought of this before" or "I didn't know this was so complicated." The amount of material they've written down, and their responses to the scenarios, has been very rich. I think they've learned more like that than (they would have) sitting in a classroom, having lecturers discussing these issues with them. So I've been really pleased with it. The problems I've had with it have been about my own inexperience with dealing with IT (Information Technology) myself and finding where they've actually posted their replies. It's 
been my ineptitude, and the fact that I have to explain to students something I'm not confident with myself. Some of them know more than I do about IT; some of them know less than I know about IT. So, I think, the problems have been technical, but the learning that has come out of it has been richer. That's where we are with it, really.

(The interview is halted at this point for reasons irrelevant to this paper.)

\section{Anecdotal Gobbet the Third}

More than a dozen years ago, with a different work hat on, I interviewed a writer for a magazine. The Twin Towers had recently fallen and I mentioned this in the interview. His response was that people needed to talk less to one another. Thirteen years later, we live in an age of mass loquacity, with hundreds of choices for ways to communicate, and it would be entirely feasible to spend an entire working day answering emails (if you were not selective). Is this an improvement, I wonder? We certainly have more information than ever before - or rather, we have faster access to information that proliferates, gets diluted, gets reformed and recontextualised - and the "art" of information filtration becomes more and more a survival instinct or a coping mechanism than a conscious decision.

\section{Steiner on Hiding}

"The patient who has hidden himself in the retreat often dreads emerging from it because it exposes him to anxieties and suffering - which is often precisely what had led him to deploy the defences in the first place..." writes John Steiner (Steiner, 2011, p. 3), who continues to say that "the first and most immediate consequence of emerging from a psychic retreat is a feeling of being exposed and observed" (Steiner, 2011, p. 3).

Considered under a different psychoanalytic spotlight, we might regard Fragile Learners as people who want to improve their lot or as people who want to hide from what they perceive to be the rigid social demands of a classroom setting. In 1993, John Steiner published Psychic Retreats (Steiner, 1993) - a seminal text in psychoanalytic literature. Employing a careful balance of clinical and theoretical material, the author ratiocinated a proposal whereby a hard-to-reach patient will create mental sanctuaries and bastions against painful and unwanted reality. This effect is achieved via the adoption and manipulation of underlying pathological organisations of the personality; subordinating oneself to these organisations is a means of coping, of retreating - or of hiding.

Though Steiner's rate of production in the years that followed might usefully be compared with that of an oyster, and though his oeuvre remains small, it is as perfectly formed as a pearl. Indeed, it is on his second full-length volume, Seeing and Being Seen (Steiner, 2011) that we might rely to gather some hints about our Fragile Learner in the online environment - and in an anxious state.

Seeing and Being Seen - a follow-up of sorts - has Steiner describing patients emerging from a psychic retreat, and concentrates on willingness, anxiety, shame and humiliation. Not for one moment would it be my intention to belittle or attempt to dilute the very real suffering that such patients must endure on a more or less uninterrupted basis; however, I do believe that there is something analogous and of interest to note with reference to our Fragile Learner. Indeed, it is my contention that some learners (and some people in general) use the Internet as a place to hide, and not hide in the sense of simply spending time away from the 'thick of it' or the 'world at large' (and note the lexical choices of density and size when we describe something from which we wish to retreat). No: this is hiding in the sense of someone experiencing anxiety. This is the Fragile Learner, using the endless reaches of the Web, not only as a place to review his opinions of himself (and anything else) - and not only to revalidate himself in the eyes of others (or the 
Lacanian Other) - but to make himself small...to make of himself something tiny in a galaxy of soothing and useless beauty. Steiner writes that

using the notion of psychic retreats enables us to recognise that pathological organisations are also represented spatially as hiding places to which patients may withdraw. Within the retreat they feel sheltered from view, and from these hiding places their objects are also not clearly visible. These retreats may appear as phantasies that are sometimes visualised in creams and other material as houses, castles, or fortresses but usually turn out to involve groups of people. Safety is then conferred by membership of a group or the protection of a powerful individual (Steiner, 2011, p. 3).

In Steiner's formulation, who is in charge? Who is (as it were) the Fragile Learner's projection of the punitive superego? "The observing figure is felt to be hostile, attacking the superiority of the narcissistic state and trying to reverse it so that the patient feels inferior" (Steiner, 2011, p. 7); and what is more, "Sometimes the persecution is more feared than the physical attack" (Steiner, 2011, p. 7) which sums up the irrational nature of anxiety as well as anything. And just to prove that there is no one way to regard any of the above, Steiner writes, "Many psychic retreats are based on feelings of resentment, which are nursed and held on to because the patient does not have the confidence to emerge from the retreat and express them as hatred and a wish for revenge" (Steiner, 2011, p. 12).

Paying due homage to Freud's classic late paper, "Analysis Terminable and Interminable" (1937), Steiner references "patients who cling to their illness and defend it by every means possible. When this happens," he argues "the patient's illness forms an essential part of the psychic retreat, and if the analyst is experienced as trying to help the patient, the pleasure of thwarting him may be more immediate than the satisfaction to be gained from change" (Steiner, 2011, p. 16).

Not only does the Fragile Learner have his own self-harming/self-protective instincts at heart and in play, he also yearns to punish those who would endeavour to help him. Therefore, at the same time as we consider why people hide, perhaps an equally appurtenant question would be: Why do people want to be seen? Why would they want to be seen? Why are we not more afraid of the Internet and of solitary confinement?

\section{Conclusion}

A scarcely-believable seven years have passed since I left the job in Education Management at that Young Offenders' Institute and yet the anxiety sparks in the short circuits of my psychic apparatus, from time to time. During periods of looming deadlines or work pressures I still dream of being at school and being incapable of handing in my Maths homework, of missed trains, planes or boats - or of being locked in a classroom with ten murderers with identical facial features.

Why should this be?

As I mentioned above, anxiety might have something of a phobic quality about it. There is no chance that memories of that prison can harm me, and yet anxiety re-visits me from time to time - created from the psychic raw sewerage of night fears, the awareness of bills due, and the recollections of mistakes made. When we examine the transcripts of the brief interviews that I conducted, we see that the time that has elapsed between the subjects being told that they were to work online and the subjects' reflections on their endeavours, the results have been of muted success at best (with Subject 2 confessing that the duration has made her even more anxious than she had been at the beginning). Despite Subject 2's reference to herself as a "dinosaur," all three interviewees were competent academic practitioners, inside the somewhat fuzzy parameters of what is usually called "middle age" (as is your author). Dwarfed by increases in work expectations, 
the subjects have shown that they are every bit as fragile as the Fragile Learner who cowers in skittish expectation of the next chapter in the book of their selfbetrayal.

Such mistrust, however, can be harnessed; determined energy may be distilled from anxiety, even if it leaves us with an analyte of unknown concentration, subject to the metaphorical titration that is the work of our punitive superegos (whether we like it or not). This paper, having a string of negatives in its abstract, will conclude with more negatives, but not with negativity. If the mood throughout seems bleak, it has been hard to avoid the melancholy that has been part of a disappointment with online learning in certain quarters. Although successes in online learning are not rare, it would be easy to defend an opinion that online learning has not developed as we might have hoped - as quickly, as redefinably. Its accouchement might not have been exactly pain-free, but now that it has been with us for the better part of two decades, does it really seem any older than two years old? The tools have developed; connection speeds have improved...but contemporary distance learning is built on fundamental pedagogic principles as old as the human race.

So is anxiety. While I am not anxious about the future (not anxious as we have discussed the condition in this paper, though concerns about ageing, loved ones and money are inevitable), I have given the examples of three interviewees who referred to their notions of time passing, in one way or another, as pertinent ingredients in their anxieties. Of course, this was hardly surprising, given the questions that they were asked; but even so, it is worth noting. Anxiety is more than their fear of change, these colleagues and our Fragile Learners alike: anxiety is the troubled glimpse of what has not or cannot come to pass, addressing an academic system in a solitary position. Perhaps it qualifies as irony the fact that with our Fragile Learners dispersed around the globe, it might be the very condition that is dreaded - anxiety - that it is the thing that they all share in common.

\section{References}

Bachelard, G. (1964). The poetics of space, trans. Maria Jolas. Boston, MA: Beacon Press.

Freud, S. (1916). Introductory lectures in psychoanalysis. In J. Strachey (Ed.), Standard Edition of the Complete Psychological Works of Sigmund Freud (Vols. 15-16). London, England: Hogarth Press.

Freud, S. (1926). Inhibitions, symptoms and anxiety. In J. Strachey (Ed.), Standard edition of the complete psychological works of Sigmund Freud (Vol. 20). London, England: Hogarth Press.

Glowinski, H. (2001). Alienation and separation. In H. Glowinski, Z. Marks, $\&$ S. Murphy(Eds), A compendium of Lacanian terms. London, England: Free Association Books.
Heidegger, M. (1962). Being and time. Oxford, England: Blackwell Publishers.

Hoult, E. C. (2012). Adult learning and la recherche féminine: Reading resilience and Hélène Cixous. New York, NY: Palgrave Macmillan.

Lacan, J. (1990). Television: A challenge to the psychoanalytic establishment. New York, NY: W. W. Norton \& Co.

Laplance, J., \& Pontalis, J. B. (2006). The language of psychoanalysis. London, England: Karnac Books.

Mathew, D. (2011). The absence of E: The role of the Internet in two distance learning programmes. Research in PostCompulsory Education, 16(4), 479-488. doi.org/10.1080/13596748.2011.62718 8 
Mathew, D. (2012, October). The role of the online personal tutor. Paper presented at the meeting of the Proceedings of the $11^{\text {th }}$ European Conference on e-Learning, The Netherlands.

Mathew, D., \& Sapsed, S. (2012). Distance learning students: Should we use technology or pedagogy to overcome work and life obstacles? E-Learning Papers. Retrieved from http://www.openeducationeuropa.eu/en/ article/Distance-Learning-Students\% 3AShould-we-use-Technology-or-Pedagogyto-Overcome-Work-and-LifeObstacles\% 3F

Meltzer, D. (1994) Sincerity and other works: Collected papers of Donald Meltzer. London, England: Karnac Books.

Obholzer, A. (1994). Managing social anxieties in public sector organizations. In A. Obholzer \& V. Z. Roberts (Eds.), The unconscious at work: Individual and organizational stress in the human (169178). New York, NY: Routledge.
Rodriguez, L. S. (2001). Autism and childhood psychosis. In H. Glowinski, Z. Marks, \& S. Murphy (Eds.), A Compendium of Lacanian Terms. London, England: Free Association Books.

Rogers, C. R. (1958). Personal thoughts on teaching and learning. Improving College and University Teaching, 6(1), 4-5.

Rycroft, C. (1995). A critical dictionary of psychoanalysis. London, England: Penguin Books.

Salecl, R. (2004). On anxiety. Abingdon, VA: Routledge.

Steiner, J. (1993). Psychic retreats. London, England: Routledge.

Steiner, J. (2011). Seeing and being seen. Hove England: Routledge.

Žižek, S. (2008). In defense of lost causes. London, England: Verso.

David Mathew works in the Centre for Learning Excellence at the University of Bedfordshire, UK, and as an independent researcher and writer. His wide areas of interest include psychoanalysis, linguistics, distance learning, prisons and online anxiety. With approximately 600 published pieces to his name, including a novel based on his time working in the education department of a maximum security prison (O My Days), he has published widely in academic, journalistic and fiction outlets. His new novel, Ventriloquists, will be published in 2014. In addition to his writing, he edits The Journal of Pedagogic Development, teaches academic writing, and he particularly enjoys lecturing in foreign countries. $\mathrm{He}$ is a member of the Tavistock Society of Psychotherapists and Allied Professionals, Evidence Informed Policy and Practice in Education in Europe (EIPPEE), and the European Association for the Teaching of Academic Writing. He was also a member of The Health Technology Assessment programme (www.hta.ac.uk), as part of the NIHR Evaluation, Trials and Studies Coordinating Centre at the University of Southampton (2009 - 2014). 